\title{
Hormonal, functional and genetic biomarkers in controlled ovarian stimulation: tools for matching patients and protocols
}

\author{
Carlo Alviggi ${ }^{*}$, Peter Humaidan ${ }^{2}$ and Diego Ezcurra ${ }^{3}$
}

\begin{abstract}
Variability in the subfertile patient population excludes the possibility of a single approach to controlled ovarian stimulation (COS) covering all the requirements of a patient. Modern technology has led to the development of new drugs, treatment options and quantitative methods that can identify single patient characteristics. These could potentially be used to match patients with the right treatment options to optimise efficacy, safety and tolerability during COS. Currently, age and follicle-stimulating hormone (FSH) level remain the most commonly used single patient characteristics in clinical practice. These variables only provide a basic prognosis for success and indications for standard COS treatment based on gross patient categorisation. In contrast, the anti-Müllerian hormone level appears to be an accurate predictor of ovarian reserve and response to COS, and could be used successfully to guide COS. The antral follicle count is a functional biomarker that could be useful in determining the dose of FSH necessary during stimulation and the success of treatment. Finally, in the future, genetic screening may allow an individual patient's response to stimulation during COS to be predicted based on genotype. Unfortunately, despite the predictive power of these measures, no single biomarker can stand alone as a guide to determine the best treatment option. In the future, hormonal, functional and genetic biomarkers will be used together to personalise COS.
\end{abstract}

Keywords: controlled ovarian stimulation, biomarkers, personalised, genetic screening

\section{Background}

Modern medical science has made great advances in the understanding and treatment of subfertility. This review is not an evidence-based meta-analysis, but rather provides our opinion on what we foresee as the future for controlled ovarian stimulation (COS) and how treatment protocols could be optimised to improve the outcome for individual patients. It is worth noting that some of the studies available in the literature and reported here have limited sample sizes and may not be adequately powered to show significance.

Novel technologies have created new ways to evaluate and treat patients and provide them with a prognosis for overcoming their subfertility. Basic and clinical research coupled with advances in technology have led to the development of a wide variety of new treatment options,

\footnotetext{
* Correspondence: alviggi@unina.it

${ }^{1}$ Centro di Sterilità ed Infertilità di Coppia, Università degli Studi di Napoli

"Federico II", Naples, Italy

Full list of author information is available at the end of the article
}

particularly in the area of COS. Follicle-stimulating hormone (FSH [urinary or recombinant (u-FSH/r-FSH)]) levels can be used alone or associated with luteinising hormone ( $\mathrm{LH}$ ) activity, which in turn can be provided in the form of human menopausal gonadotrophin (hMG), recombinant human LH ( $\mathrm{r}-\mathrm{hLH})$ or human chorionic gonadotrophin (hCG [urinary or recombinant (u-hCG/rhCG)]). In addition, the optional use of steroid hormones such as progesterone, oestrogen, testosterone or dehydroepiandrosterone (DHEA), and even the possibility of growth hormone treatment, could be considered following further research. Taken together, all these options tend to increase the complexity of treatment decisions. The discussion around gonadotrophin-releasing hormone ( $\mathrm{GnRH}$ ) agonist versus antagonist protocols during $\mathrm{COS}$ is another example highlighting the expanding number of treatment options and the urgent need to develop a rationale for making the best choice of treatment for each single patient.

\section{Biomed Central}


Currently, demographic and anthropomorphic data are the primary sources of information used to provide a prognosis and guide treatment. Along with basic medical and nutritional information, functional, hormonal and genetic biomarkers are tools that could provide more accurate diagnostic and prognostic information. Nonetheless, there is currently no consensus in the literature around the world as to how these newly available tools should be applied for a personalised treatment plan in order to improve the outcome of COS. Presently, general patient characteristics determine treatment, disregarding unique characteristics that might influence the needs of the individual patient, and thus, the chance of success. Empirical decision-making based on broad generalisations translates to similar patients receiving similar treatments. Thus, conventional factors like age and previous cycle data are used to make vital treatment decisions. Quantitative biomarkers are utilised mainly to predict prognosis and to inform patient counselling, but the strong potential of these indicators as tools to personalise COS is often underestimated [1].

The multidimensional variability of the subfertile patient population renders a single treatment approach unsuitable to dealing with a wide range of patient characteristics. This diversity in the fertility patient population, together with the ever-expanding number of treatment options (Table 1), creates both the need and the opportunity for personalised treatment, including an individualised approach to COS. The goal of 'personalised COS' can be achieved by taking advantage of the information provided by advancing science and new technologies. Using hormonal, functional and genetic biomarkers to develop a standard method of customising COS will make it possible to consistently match the correct treatment to the right patient. The improvements in treatment decision-making will lead to less burdensome protocols, less risk of adverse events, better outcomes and cost efficiency.

\section{How can we predict ovarian response and personalise treatment?}

\section{Age versus biomarkers}

Age is the most commonly used predictor of fertility; increasing age inevitably results in substantial germ cell loss by the age of 40 [2]. Statistics for pregnancy, live birth and singleton live birth rate also decline rapidly from the mid-thirties on [3]. However, even though age is clearly linked to declining fertility, it does not affect all women equally. On an individual basis, the chronological age of an individual may not be as valuable a predictor of fertility as their 'biological age', which is defined by the hormonal and functional profiles. Thus, biomarkers quantifying hormonal and functional profiles are more useful as prognostic factors than age alone when predicting response and choosing treatment strategy. Finally, genetic screening can provide specific information about a woman's reproductive system that would not be accurately predicted by age, hormonal or functional biomarkers. By considering hormonal (FSH and anti-Müllerian hormone $[\mathrm{AMH}]$ ), functional (antral follicle count $[\mathrm{AFC}])$, and genetic biomarkers in combination, a complete picture of an individual patient's overall reproductive status can be formulated to provide a basis of designing an optimal treatment plan.

\section{Hormonal biomarkers: $\mathrm{AMH}$}

Inhibin-B, FSH and AMH are hormonal markers that can be used to predict ovarian response to COS and success with assisted reproductive technology (ART).

Table 1 Variables in the choice of COS protocol

\begin{tabular}{|c|c|c|}
\hline $\begin{array}{l}\text { Factors determining individual patients' response to } \\
\text { ovarian stimulation }\end{array}$ & $\begin{array}{l}\text { Treatments used in ovarian } \\
\text { stimulation protocols }\end{array}$ & Protocol variations \\
\hline $\begin{array}{l}\text { Demographics and anthropometrics } \\
\text { (e.g., age, BMI and race) }\end{array}$ & $\begin{array}{c}\text { Gonadotrophins: } \\
\text { r-FSH/LH/hCG } \\
\text { u-FSH/LH/hCG }\end{array}$ & $\begin{array}{l}\text { GnRH agonist protocol } \\
\text { (long, short and micro flare) }\end{array}$ \\
\hline Genetic profile & $\begin{array}{c}\text { GnRH analogues: } \\
\text { Agonists } \\
\text { Antagonists }\end{array}$ & $\begin{array}{l}\mathrm{GnRH} \text { antagonist protocol } \\
\text { (standard, mild and modified natural) }\end{array}$ \\
\hline Health status & $\begin{array}{c}\text { Steroid hormones: } \\
\text { Progesterone } \\
\text { Oestradiol } \\
\text { Testosterone } \\
\text { DHEA }\end{array}$ & Agonist-antagonist protocol \\
\hline Cause of subfertility & $\begin{array}{l}\text { Other treatments: } \\
\text { Aromatase inhibitors } \\
\text { Growth hormone } \\
\text { Clomiphene citrate }\end{array}$ & Natural cycles \\
\hline \multicolumn{3}{|l|}{ Duration of subfertility } \\
\hline Nutrition & & \\
\hline
\end{tabular}

$\mathrm{BMI}=$ body mass index; $\mathrm{COS}$ = controlled ovarian stimulation; DHEA = dehydroepiandrosterone; GnRH = gonadotrophin releasing hormone; hCG = human chronic gonadotrophin; $\mathrm{LH}=$ luteinising hormone; r-FSH = recombinant follicle-stimulating hormone; u-FSH = urinary follicle-stimulating hormone. 
Although FSH levels are more commonly used to evaluate a woman's probable response to COS, AMH (as a paracrine product of immature follicles) is a more direct measure of ovarian status compared with other endocrine reproductive hormones. AMH is primarily produced by the pre-antral and small antral follicles, and correlates with the number of primordial follicles at the gonadotrophin-independent stage of follicular development $[4,5]$.

A small study showing the potential use of AMH measurement in a routine in-vitro fertilisation (IVF) programme prospectively enrolled 316 patients and considered 132 oocyte retrievals in women undergoing a $\mathrm{GnRH}$ agonist long protocol. When the calculated optimal AMH cut-off of $\leq 1.26 \mathrm{ng} / \mathrm{ml}$ was used to predict responses to COS, it was found to have a $97 \%$ sensitivity for predicting poor responses $(<4$ oocytes retrieved) and a $98 \%$ accuracy in predicting a normal COS response. These findings indicate that circulating $\mathrm{AMH}$ levels may be a good indicator of ovarian reserve, and are highly correlated with ovarian response to COS [6].

In the first study designed to evaluate the use of a hormonal biomarker to determine treatment strategy, Nelson and colleagues compared the safety, tolerability and success rates of different AMH-based COS strategies in two IVF centres. In this prospective cohort study, 538 women were stratified according to their $\mathrm{AMH}$ levels prior to COS (low: $1-<5 \mathrm{pmol} / \mathrm{l}$, medium: 5-15 pmol/l and high: > $15 \mathrm{pmol} / \mathrm{l})$. In both centres, doses were similarly determined by each patient's AMH level; high, medium or low doses of FSH were given to women with low, medium and high AMH levels, respectively. However, in one centre, the choice between the $\mathrm{GnRH}$ agonist long protocol versus a milder $\mathrm{GnRH}$ antagonist protocol was also determined based on $\mathrm{AMH}$ levels. Specifically, most patients at the first centre (regardless of AMH level) were treated with a $\mathrm{GnRH}$ agonist long protocol, while in the second centre, those with high or low AMH levels were treated with a $\mathrm{GnRH}$ antagonist protocol.

In both centres, low AMH levels were associated with a reduced clinical pregnancy rate (CPR), but the cohort of low AMH patients receiving the antagonist protocol had a median duration of treatment of 10 days with a cancellation rate of $5 \%$ compared with a duration of 14 days and cancellation rate of $19 \%$ for the group treated with GnRH agonist long protocol. As expected, women from both centres with normal AMH levels had similar good outcomes with no poor response and no incidence of excessive stimulation. However, the group of patients with high AMH levels, similar to the group with low AMH levels, had better outcomes using the GnRH antagonist compared with the agonist protocol. No patients with high AMH who underwent the GnRH antagonist protocol were hospitalised due to ovarian hyperstimulation syndrome (OHSS) compared with $13.9 \%$ in the high AMH level group who received the $\mathrm{GnRH}$ agonist long protocol. In addition, use of the antagonist protocol did not result in any cases of 'total freeze' to avoid OHSS. Furthermore, the improvements in COS safety and tolerability observed with the GnRH antagonist protocol were accompanied by higher CPRs in both the low AMH (11.1\% vs 18.7\%) and high AMH (40.1\% vs $63.6 \%)$ groups [7]. The data from this study should be confirmed in large, randomised, controlled trials, but suggest that AMH may be used as a precise and reliable predictive tool to determine treatment strategies that can improve safety, tolerability and pregnancy outcomes (Figure 1).

Currently, a limiting factor in the use of $\mathrm{AMH}$ as a biomarker is the variability seen between commercial kits and variation in results reported from different

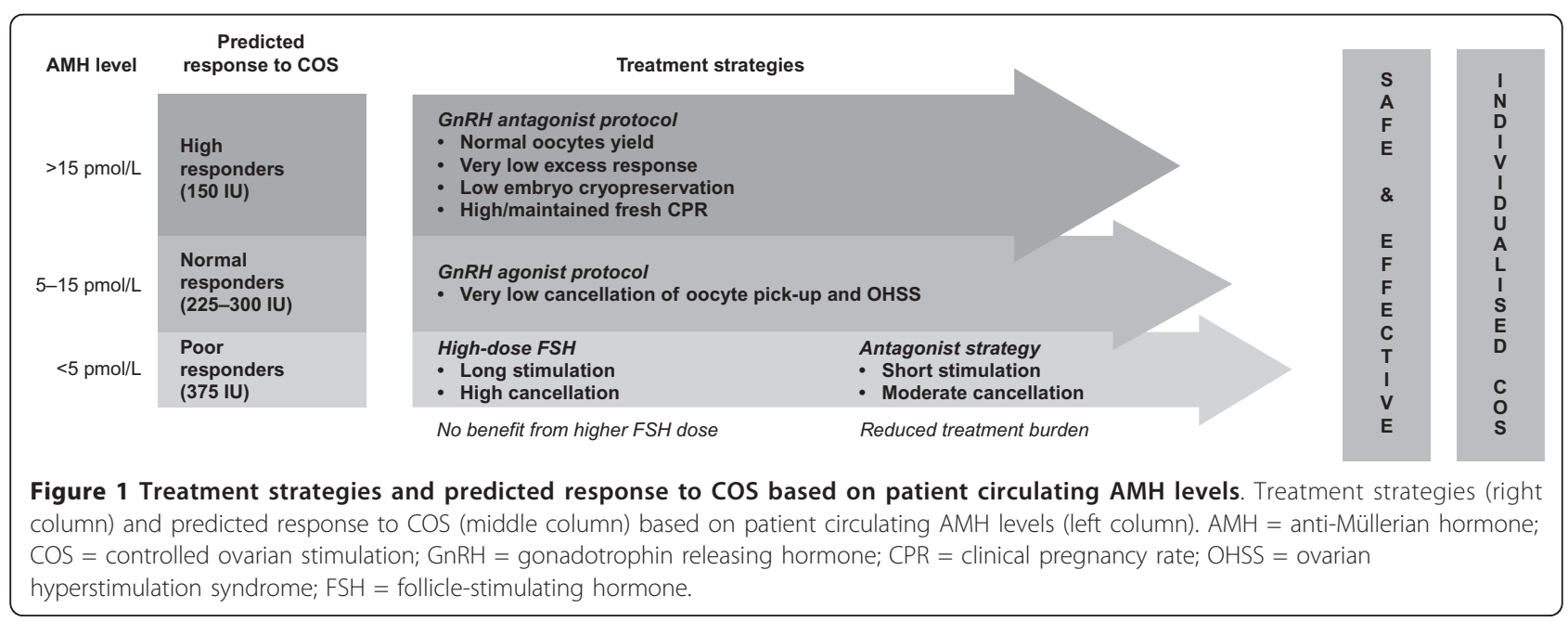


laboratories [8]. This variability may be one of the reasons for the lack of consensus on the cut off values of AMH when deciding whether or not to proceed with ART.

\section{Functional biomarkers: AFC}

The number of antral follicles detected by ovarian ultrasound has gained acceptance as an indicator of ovarian reserve, a COS response prognostic tool and predictor of IVF success $[9,10]$. In a study including 149 treatment cycles, Chang and colleagues found that AFC declined with age and was negatively correlated to day $3 \mathrm{FSH}$ and cancellation rate. In the same study, when patients were grouped by AFC (AFC < 4, 4-10 or > 10), the mean number of retrieved oocytes was 2.0, 6.3 and 14.0, and ongoing pregnancy rates were $0 \%, 13.2 \%$ and $26.3 \%$, respectively [11].

Another study investigated 113 women undergoing their first ART cycle. In this group, AFC was found to be significantly associated with AMH levels and the number of retrieved oocytes, with the number of follicles between 5 and $6 \mathrm{~mm}$ having the highest correlation to both endpoints. AFC was also found to be predictive of poor responses to COS, with the number of follicles sized 2-4 mm, 2-5 mm, 2-8 $\mathrm{mm}$ and $2-10 \mathrm{~mm}$ being approximately equal in predicting response [12].

AFC is a relatively easy-to-perform technique that is widely accessible due to the availability of ultrasound equipment. Despite its general acceptance as a predictor of ovarian response, the routine use of AFC has been hampered by the lack of a standard methodology that would permit valid comparisons of data from different centres, and thus facilitate the consistent assessment of AFC. In order to address this issue, Broekmans and colleagues suggested recommendations for the standardisation of AFC assessment in routine clinical practice. Basic clinical and technical requirements for AFC evaluation were defined and a systematic method of measuring and counting antral follicles in clinical practice was proposed (Table 2) [13]. Hopefully, as these guidelines are adopted around the world, the accumulation of standardised, universally relevant AFC data will make this quantitative, functional biomarker an even more useful prognostic tool.

Similarly to AMH, AFC was initially used as a simple prognostic factor and subsequently become a decisionmaking variable. Following the initial establishment of $\mathrm{AFC}$ as a reliable prognostic factor, its use in matching patients with COS protocols was hypothesised. A first

Table 2 The basic clinical and technical requirements for assessment of the AFC in clinical practice (reproduced with permission from Broekmans et al.

\begin{tabular}{|c|c|}
\hline \multicolumn{2}{|l|}{ Considerations for the assessment of the AFC in clinical practice } \\
\hline Clinical considerations & Technical considerations \\
\hline $\begin{array}{l}\text { Select patients with regular menstrual cycles with no co-existing } \\
\text { pathological condition that could technically affect the counting of } \\
\text { follicles, such as ovarian endometriosis or previous ovarian surgery }\end{array}$ & $\begin{array}{l}\text { A limited number of personnel, appropriately trained in transvaginal } \\
\text { sonography should perform AFCs in each unit } \\
\text { Real-time, two-dimensional imaging is adequate }\end{array}$ \\
\hline \multirow[t]{7}{*}{$\begin{array}{l}\text { Count follicles between days } 2 \text { and } 4 \text { of a spontaneous menstrual } \\
\text { or oral contraceptive cycle to avoid the effect of intra-cycle variation } \\
\text { Include all antral follicles of } 2-10 \mathrm{~mm} \text { in diameter }\end{array}$} & $\begin{array}{l}\text { Use a transvaginal transducer } \\
\text { Use a probe with a minimum frequency of } 7 \mathrm{MHz} \text {, which is } \\
\text { maintained in an adequate condition and able to resolve a structure } \\
\text { of } 2 \mathrm{~mm} \text { in diameter }\end{array}$ \\
\hline & Use a systematic process for counting antral follicles: \\
\hline & $\begin{array}{l}\text { 1. Identify the ovary } \\
\text { 2. Explore the dimensions in two planes (perform a scout sweep) } \\
\text { Decide on the direction of the sweep to measure and count follicles } \\
\text { 3. Measure the largest follicle in two dimensions }\end{array}$ \\
\hline & A. If the largest follicle is $\leq 10 \mathrm{~mm}$ in diameter: \\
\hline & $\begin{array}{l}\text { i. Start to count from outer ovarian margin of the sweep to } \\
\text { the opposite margin } \\
\text { ii. Consider every round or oval transonic structure within } \\
\text { the ovarian margins to be a follicle } \\
\text { iii. Repeat the procedure with the contralateral ovary } \\
\text { iv. Combine the number of follicles in each ovary to obtain } \\
\text { the AFC }\end{array}$ \\
\hline & B. If the largest follicle is $>10 \mathrm{~mm}$ in diameter: \\
\hline & $\begin{array}{l}\text { i. Further ascertain the size range of the follicles by } \\
\text { measuring each sequentially smaller follicle, in turn, until a } \\
\text { follicle with a diameter of } \leq 10 \mathrm{~mm} \text { is found } \\
\text { ii. Perform a total count (as described) regardless of follicle } \\
\text { diameter } \\
\text { iii. Subtract the number of follicles of }>10 \mathrm{~mm} \text { from the } \\
\text { total follicle count }\end{array}$ \\
\hline
\end{tabular}


attempt to address this was the Consolidated Standards of Reporting Trials (CONSORT) analysis, which aimed to determine whether specific factors could optimally predict a response to stimulation in ART and then develop a treatment algorithm to determine the optimal starting dose of r-FSH [14]. Results from a subsequent CONSORT study demonstrate that AFC, combined with other patient characteristics, can be used to personalise treatment and maximise COS response and, at the same time, minimise patient risk and treatment burden [15]. The CONSORT dosing algorithm was used to calculate the dose of r-FSH with 37.5 IU incremental increases based on basal FSH, body mass index (BMI), age and AFC. Patients were assigned to r-FSH doses of $75 \mathrm{IU}(\mathrm{n}=48), 112.5 \mathrm{IU}(\mathrm{n}=45), 150 \mathrm{IU}(\mathrm{n}=34)$, 187.5 IU $(\mathrm{n}=24)$ and 225 IU $(\mathrm{n}=10)$. Oocytes retrieved per cycle were 8.5, 8.0, 10.0, 12.0 and 8.0, and CPRs per cycle of $31.3 \%, 31.1 \%, 35.3 \%, 50.0 \%$ and $20.0 \%$, respectively, were observed [15]. The favourable retrieval and pregnancy rates seen in this preliminary study demonstrate the successful use of multiple biomarkers, including AMH, to achieve effective individualised COS (Figure 2).

\section{Genetic biomarkers}

The influence of genetic research continues to shape the scientific and medical landscape. Pharmacogenetics is the science of predicting drug effects based on the genotype of an individual. In the future, the treatment of a patient could be based on her individual DNA. Presently, even though the biological response to any given

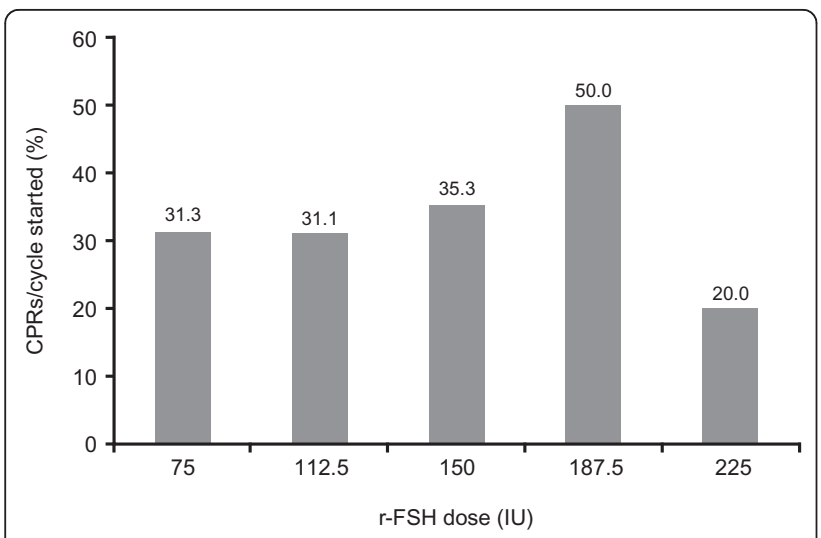

Figure 2 Treatment strategies and predicted response to $\operatorname{COS}$ based on patient circulating AMH levels. Pregnancy outcomes after COS with r-FSH doses determined by basal FSH, BMI, age and AFC using the CONSORT dose calculator algorithm. AFC = antral follicle count; FSH = follicle-stimulating hormone; $A S N=$ asparagine; Ser $^{680}=$ serine $^{680} ; \mathrm{BMI}=$ body mass index; CONSORT $=$

Consolidated Standards of Reporting Trials; COS = controlled ovarian stimulation; r-FSH = recombinant follicle-stimulating hormone. Adapted from Olivennes et al. 2009 [14]. drug may be influenced by hundreds of genes, progress is being made in the identification of specific genetic variances, called single nucleotide polymorphisms (SNPs) that can predict the safety and effectiveness of certain drugs in individual patients. In the field of reproductive health, hormonal and functional biomarkers are more established as tools to predict ovarian response, but in the future, genetic biomarkers may well be the best predictive tool to guide individualised treatment.

Genetic traits that influence fertility may not have visible clinical signs or abnormalities. If a patient's genetic profile also diminishes her response to fertility treatment, the failure to consider the genotype when designing the treatment consequently leads to a suboptimal treatment strategy. For example, a subset of young, normogonadotrophic IVF patients may produce an adequate number of retrieved oocytes and normal oestrogen levels, but not respond to COS as anticipated. These women require high doses of FSH (> 2,500 IU) over long treatment periods and, despite good prognostic indicators, have low implantation and pregnancy rates [16-19]. One possible reason for this hyporesponder 'normal' population is that they may have a genetic predisposition to a reduced sensitivity to FSH.

FSH and LH synergistically regulate normal ovarian function and oocyte development, and the disruption of either hormonal signal could have an impact on normal ovarian function and stimulation response. Thus, the genetic variability that affects the innate activity of these hormones could provide valuable predictive information and help guide COS treatment choices. Mutations in the genes coding for $\mathrm{LH}$ [20-24], the LH receptor [25-27] and the FSH receptor [28-32] have been identified as possible causes of subfertility, as well as factors that may influence fertility treatment.

A common variant of the $\beta$ subunit of the LH molecule $(\mathrm{v}-\mathrm{LH})$ is identified by an additional sulphonated sugar at asparagine (Asn)-13 [33]. The v-LH polymorphism is found in populations worldwide, but has so far been most commonly identified in northern European countries [34]. There is clear clinical evidence that the $\mathrm{v}$-LH polymorphism affects $\mathrm{FSH}$ sensitivity and the ovarian response to COS. For example, in a group of 60 normogonadotrophic women aged 18-37 years with normal menstruation, basal FSH $\leq 10 \mathrm{IU} / \mathrm{l}$ and at least five oocytes retrieved, one homozygote and seven v-LH heterozygotes were identified. When these women were stratified by the cumulative dose of FSH used $(>3,500$ IU, 2,000-3,500 IU or $<2,000 \mathrm{IU})$, one heterozygote fell in the middle range with the rest having had doses greater than 3,500 IU [24]. In another study of 204 normogonadotrophic women, $21 \mathrm{v}-\mathrm{LH}$ heterozygotes and three v-LH homozygotes were identified. The FSH dose needed was positively correlated with the presence of 
the mutation, with a gradient in which the v-LH homozygotes and heterozygotes received a substantially higher cumulative dose when compared with the wild-type carriers (Figure 3) [35]. These preliminary analyses suggest that the v-LH genotype may help identify a subgroup of potential COS hyporesponders who are less sensitive to FSH, and who would benefit from LH supplementation rather than stimulation with higher doses of FSH.

Hyposensitivity to FSH may also be caused by a genetic variant of the FSH receptor. Two FSH receptor variants that have SNPs in the coding region have been identified and well characterised [36]. The SNP known as the Serine $^{680}\left(\mathrm{Ser}^{680}\right)$ variant causes the replacement of Asn with Ser at the 680 position, which is located in the intracellular domain of the FSH receptor protein [37]. Consistent with reduced sensitivity to endogenous FSH, carriers of this trait have higher FSH levels throughout most of the menstrual cycle, and a significant increase in both total menstrual cycle length and number of antral follicles [29]. When this SNP was studied in a group of 161 women below the age of 40 years undergoing ART, the distribution was $45 \%$ for the wild-type (Asn/Asn), 29\% for the heterozygote (Asn/Ser ${ }^{680}$ ) and $26 \%$ for the homozygote $\left(\mathrm{Ser}^{680} / \mathrm{Ser}^{680}\right)$. Although peak oestradiol levels, numbers of pre-ovulatory follicles and numbers of retrieved oocytes were similar in the three groups, basal FSH levels were significantly higher for carriers of the Ser ${ }^{680}$ variant (6.4 IU/l, 7.9 IU/I and $8.3 \mathrm{IU} / \mathrm{l}$ for the Asn/ Asn, Asn $/ \mathrm{Ser}^{680}$ and $\mathrm{Ser}^{680} / \mathrm{Ser}^{680}$ groups, respectively). Furthermore, both the heterozygotes and homozygotes required significantly more FSH during COS compared with the wild-type group (Figure 4) [38]. The second receptor variant, known as the Alanine ${ }^{307}\left(\mathrm{Ala}^{307}\right)$ variant, is generated through substitution of threonine (Thr) with Ala at the 307 position, located in the extracellular domain of the FSH receptor [37]. There is a very strong linkage disequilibrium between the two SNPs. This

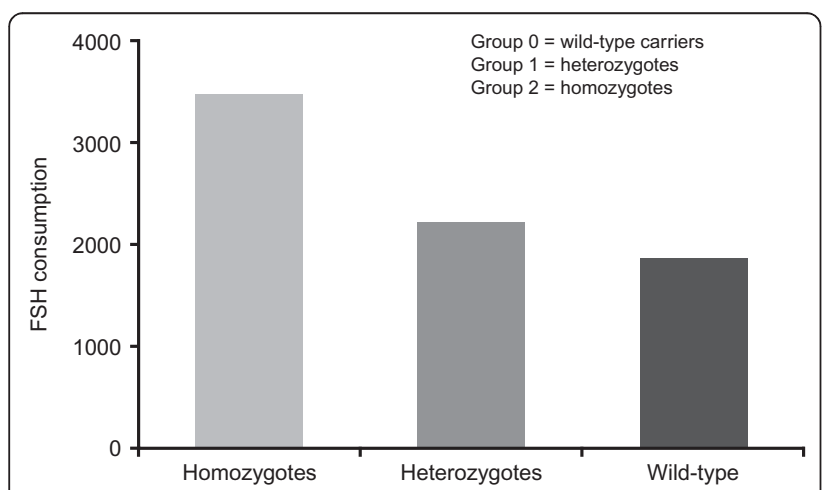

Figure 3 Association between v-LH and FSH consumption. FSH $=$ follicle-stimulating hormone; $\mathrm{v}$ - $\mathrm{LH}=$ variant luteinising hormone. Adapted from Alviggi et al. 2009 [34].

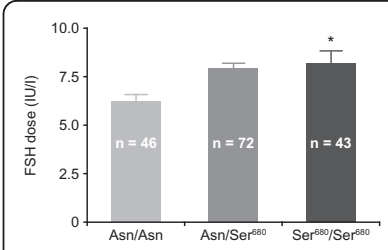

$\cdot p<0.05$

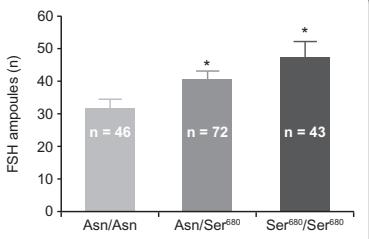

$\cdot P<0.05$
Figure 4 Basal FSH levels and ampoules of FSH used in COS for patients with variants of the FSH receptor. Basal FSH levels (left panel) and ampoules of FSH used in COS (right panel) for homozygote wild-type (Asn/Asn), heterozygote (Asn/Ser ${ }^{680}$ ) and homozygote $\left(\mathrm{Ser}^{680} / \mathrm{Ser}^{680}\right)$ carriers of the Ser ${ }^{680}$ variant of the FSH receptor. $\mathrm{ASN}=$ asparagine; $\mathrm{CPRs}=$ clinical pregnancy rates; $\mathrm{COS}=$ controlled ovarian stimulation; $\mathrm{FSH}=$ follicle-stimulating hormone; $r$ $\mathrm{FSH}=$ recombinant follicle-stimulating hormone; Ser ${ }^{680}=$ Serine $^{680}$. Adapted from Perez Mayorga et al. 2000 [37].

means that women who possess $\mathrm{Thr}^{307}$ nearly always have $\mathrm{Asn}^{680}$ present on the same allele, and women who have $\mathrm{Ala}^{307}$ have $\mathrm{Ser}^{680}$ on the same allele [36]. The link between FSH receptor SNPs and polycystic ovarian stimulation (PCOS) has been studied extensively; however, there is some variation in the results seen. Some studies have demonstrated higher levels of patients with $\mathrm{Ser}^{680}$ in the PCOS population [39], whereas other investigators have shown differences in basal levels of FSH depending on the presence of the SNP [40]. Interestingly, it has recently been demonstrated that PCOS patients with the $\mathrm{Ser}^{680}$ mutation have a natural resistance to clomiphene citrate [41]. This may prove to be very important in the field of ovarian stimulation in the future with clinicians devising their COS protocols according to factors including FSH receptor genotype. Additionally, the effect of the $\mathrm{Ser}^{680}$ SNP has been studied in the general population receiving subfertility treatment and results have been reviewed previously [42]. Studies have reported conflicting results with some demonstrating worse outcomes with the mutation and others demonstrating positive outcomes. For example one study demonstrated higher pregnancy rates in the patients with Asn680 [43] and another showed higher pregnancy rates in patients with Ser680 [44].

An additional study looked at FSH-induced oestradiol levels in women who were homozygous for the $\mathrm{Ser}^{680}$ variant compared with women with the wild-type (Asn/Asn). This represented the first attempt to develop a pharmacogenomical approach to COS. $\operatorname{Ser}^{680} / \mathrm{Ser}^{680}$ carriers were randomly allocated to two subgroups to receive a daily FSH dose of $150 \mathrm{IU}$ or $225 \mathrm{IU}$, respectively. Age and BMImatched Asn/Asn carriers, receiving a daily dose of 150 IU, constituted a third (control) group. Even though the treatment details, number of oocytes retrieved and fertilisation rates were similar, the wild-type group had higher oestradiol production after treatment with 150 IU/day of 
FSH compared with the $\mathrm{Ser}^{680}$ group given the same dose; conversely, when $\mathrm{Ser}^{680} / \mathrm{Ser}^{680}$ carriers were treated with $225 \mathrm{IU} /$ day, this difference disappeared [31]. These findings are consistent with carriers of the $\mathrm{Ser}^{680} / \mathrm{Ser}^{680}$ variant experiencing lower biological activity of both endogenous and exogenous FSH due to lower sensitivity of the FSH receptor to FSH. However, it should be noted that two further studies did not confirm that adjustment of the starting dose of FSH improved the hormonal response $[43,44]$. Despite this, the findings of FSH starting dose modification studies raise an intriguing question about the interpretation of isolated markers, including AFC. In fact, the current literature suggests that AFC is effective in predicting ovarian response and choosing the right FSH dose; nevertheless, a pharmacogenomical approach to COS strongly indicates that, in at least one out of four patients with normal AFC (which reflects the frequency of $\mathrm{Ser}^{680} / \mathrm{Ser}^{680}$ ), the optimal FSH dose should be higher. This provides further support that AFC and genetic approaches should be integrated into determination of COS treatment protocols.

In addition to the two SNPs described above, there are also many genotypic SNPs found in the introns and untranslated regions of the FSH receptor gene; however, it is not currently known what physiological effects these mutations confer [36]. Further mutations have been identified in young women $(<35$ years) undergoing $\mathrm{COS}$ in the form of receptor splice variants [32]. FSH receptor messenger RNA was isolated from the cumulus cells of women who demonstrated high or low response to FSH when treated with a GnRH agonist long protocol. Abnormal splicing products were identified that affected the ligand-binding extracellular domain. One variant was associated with a low response to $\mathrm{FSH}$, and another variant was associated with a high FSH response [32].

\section{Patient profiling}

Each patient's individual characteristics must be considered in order to determine treatment that will provide her with an optimal response to COS, while keeping the adverse events and treatment burden as low as possible. Specifically, the hormonal, functional and genetic biomarkers described here can provide the critical information needed to personalise treatment to best serve the individual patient. AMH represents ovarian reserve and can help determine how much longer a woman will remain fertile and if ART is a viable option. AFC represents the number of follicles that are maturing in each cycle and provides a prediction of the response to COS. Finally, the individual patient's genetic profile defines the underlying physiology that determines the meaning and interpretation of hormonal and functional biomarkers like $\mathrm{AMH}$ and AFC, predicting the effectiveness of FSH when stimulating the ovaries (Table 3 ).

In addition to using the patient's individual characteristics to determine which treatment protocols should be selected, this patient-specific approach could potentially be used to determine how treatment protocols are administered. The short, ultrashort, micro-flare and stop GnRH agonist protocols are all adaptations of the standard protocol for COS, generated by adjusting the timing and dose of GnRH agonist administration $[45,46]$. Preparation of the endometrium is also a crucial step in the success of IVF. Further analysis of hormonal, functional and genetic biomarkers and their relationships with patient response to variations in treatment protocols could be used in the future, and additional clinical data are required to support this hypothesis.

\section{Conclusions}

Individual patient characteristics can be predictive of ovarian response, and these factors must be used to optimise the individual treatment regimen. AMH and AFC are good predictors of ovarian response to COS, and may be valuable in deciding which protocol and dose to use for COS. Additionally, initial data indicate that the use of AMH to determine protocol selection may reduce the incidence of OHSS, although further studies are required to confirm this. The hyposensitivity to FSH in a subset of women undergoing the $\mathrm{GnRH}$ agonist protocol despite other normal indicators was described by De Placido and colleagues [17]. It is possible that this condition may be caused by genetic polymorphisms of LH, the FSH receptor or the LH receptor. Thus, genetic testing of normogonadotrophic women showing reduced sensitivity to FSH (e.g., a high FSH dose in previous cycles) may assist in tailoring subsequent treatment. Patients could be given higher doses of FSH if they are found to carry the $\operatorname{Ser}^{680}$ variant, or

Table 3 Patient genetic profiles: interpretation of physiology and biomarker levels

\begin{tabular}{ll}
\hline Genetic profile & Interpretation of genetic profile \\
\hline Low AMH levels; low AFC & $\begin{array}{l}\text { Suggests that even high doses of FSH would be ineffective and that LH would not improve results } \\
\text { Patient would benefit from counselling to better understand her limited chances of success }\end{array}$ \\
$\begin{array}{ll}\text { FSH receptor variant (eg. Ser } \\
\text { levels; good AFC }\end{array}$ & $\begin{array}{l}\text { Suggests a good prognosis, but it also predicts a genetic hyposensitivity to FSH that should be } \\
\text { considered when formulating COS treatment }\end{array}$ \\
v-LH (variant in $\beta$ subunit of LH receptor) & Suggest that a patient might benefit from LH supplementation during COS \\
\hline
\end{tabular}

$\mathrm{AMH}=$ anti-Müllerian hormone; AFC = antral follicle count. 
have LH added to their treatment if they are found to carry the v-LH polymorphism. As technology progresses and more powerful analytical tools are developed, predicting ovarian response using a single biomarker will not be sufficient to make the most accurate prognosis or to formulate a personalised treatment plan. In the future, the combination of hormonal, functional and genetic testing will be needed to ensure that the right treatment protocol is provided to the right patient. Finally, the patient's response to treatment should be monitored closely to determine if further tailoring of the personalised treatment plan is required.

\section{List of abbreviations}

AFC: antral follicle count; Ala: alanine; AMH: anti-Müllerian hormone; ART: assisted reproductive technology; Asn: asparagine; BMI: body mass index; CONSORT: Consolidated Standards of Reporting Trials; COS: controlled ovarian stimulation; CPR: clinical pregnancy rate; DHEA: dehydroepiandrosterone; DNA: deoxyribonucleic acid; FSH: folliclestimulating hormone; GnRH: gonadotrophin-releasing hormone; hCG: human chorionic gonadotrophin; hMG: human menopausal gonadotrophin; IVF: invitro fertilisation; LH: luteinising hormone; OHSS: ovarian hyperstimulation syndrome; PCOS: polycystic ovary syndrome; r-FSH: recombinant folliclestimulating hormone; r-hCG: recombinant human chorionic gonadotrophin; $r$-hLH: recombinant human luteinising hormone; RNA: ribonucleic acid; Ser: serine; SNP: single nucleotide polymorphism; Thr: threonine; u-FSH: urinary follicle-stimulating hormone; u-hCG: urinary human chorionic gonadotrophin; v-LH: variant luteinising hormone

\section{Acknowledgements}

The authors would like to thank Dr Agnese Fiorentino for her helpful discussion of the manuscript. Medical writing assistance was provided by Michael Bankson and Kirsty Ratcliffe of Gardiner-Caldwell Communications, Macclesfield, UK. Funding for medical writing support was provided by Merck-Serono.

\section{Author details}

${ }^{1}$ Centro di Sterilità ed Infertilità di Coppia, Università degli Studi di Napoli "Federico II", Naples, Italy. ${ }^{2}$ The Fertility Clinic, The University Hospital Odense $(\mathrm{OUH})$, Denmark. ${ }^{3}$ Fertility and Endocrinology Business Unit, Merck Serono S. A., Geneva, Switzerland.

\section{Authors' contributions}

$\mathrm{CA}, \mathrm{PH}$ and $\mathrm{DE}$ all contributed their opinions and were involved in the reviewing of the literature and writing of the manuscript. All authors read and approved the final manuscript.

\section{Competing interests}

$\mathrm{CA}$ and $\mathrm{PH}$ have no competing interests to declare. $\mathrm{DE}$ is an employee of Merck Serono S.A., Geneva.

Received: 12 August 2011 Accepted: 6 February 2012

Published: 6 February 2012

\section{References}

1. Ezcurra D, Bosch E: Individualised controlled ovarian simulation (iCOS): maximising success rates for assisted reproductive technology patients. Reprod Biol Endocrinol 2011, 21, 9:82.

2. Baker JW, Morgan RL, Peckham MJ, Smithers DW: Preservation of ovarian function in patients requiring radiotherapy for para-aortic and pelvic Hodgkin's disease. Lancet 1972, 1:1307-1308.

3. Akande VA, Fleming CF, Hunt LP, Keay SD, Jenkins JM: Biological versus chronological ageing of oocytes, distinguishable by raised FSH levels in relation to the success of IVF treatment. Hum Reprod 2002, 17:2003-2008.
4. La Marca A, Broekmans FJ, Volpe A, Fauser BC, Macklon NS: Anti-Mullerian hormone (AMH): what do we still need to know? Hum Reprod 2009, 24:2264-2275.

5. La Marca A, Sighinolfi G, Radi D, Argento C, Baraldi E, Artenisio AC, Stabile G, Volpe A: Anti-Mullerian hormone (AMH) as a predictive marker in assisted reproductive technology (ART). Hum Reprod Update 2010, 16:113-130.

6. Gnoth C, Schuring AN, Friol K, Tigges J, Mallmann P, Godehardt E: Relevance of anti-Mullerian hormone measurement in a routine IVF program. Hum Reprod 2008, 23:1359-1365.

7. Nelson SM, Yates RW, Lyall H, Jamieson M, Traynor I, Gaudoin M, Mitchell P, Ambrose P, Fleming R: Anti-Mullerian hormone-based approach to controlled ovarian stimulation for assisted conception. Hum Reprod 2009, 24:867-875.

8. Fréour T, Mirallié $S$, Bach-Ngohou K, Denis M, Barrière P, Masson D: Measurement of serum anti-Müllerian hormone by Beckman Coulter ELISA and DSL ELISA: comparison and relevance in assisted reproduction technology (ART). Clin Chim Acta 2007, 375:162-4.

9. Chang MY, Chiang CH, Chiu TH, Hsieh TT, Soong YK: The antral follicle count predicts the outcome of pregnancy in a controlled ovarian hyperstimulation/intrauterine insemination program. J Assist Reprod Genet 1998, 15:12-17.

10. Hendriks DJ, Mol BW, Bancsi LF, te Velde ER, Broekmans FJ: Antral follicle count in the prediction of poor ovarian response and pregnancy after in vitro fertilization: a meta-analysis and comparison with basal folliclestimulating hormone level. Fertil Steril 2005, 83:291-301.

11. Chang MY, Chiang $\mathrm{CH}$, Hsieh $\Pi$, Soong YK, Hsu KH: Use of the antral follicle count to predict the outcome of assisted reproductive technologies. Fertil Steril 1998, 69:505-510.

12. Jayaprakasan K, Deb S, Batcha M, Hopkisson J, Johnson I, Campbell B, Raine-Fenning $\mathrm{N}$ : The cohort of antral follicles measuring $2-6 \mathrm{~mm}$ reflects the quantitative status of ovarian reserve as assessed by serum levels of anti-Mullerian hormone and response to controlled ovarian stimulation. Fertil Steril 2010, 94:1775-1781.

13. Broekmans FJ, de Ziegler D, Howles CM, Gougeon A, Trew G, Olivennes F: The antral follicle count: practical recommendations for better standardization. Fertil Steril 2010, 94:1044-1051.

14. Howles CM, Saunders H, Alam V, Engrand P, FSH Treatment Guidelines Clinical Panel: Predictive factors and a corresponding treatment algorithm for controlled ovarian stimulation in patients treated with recombinant human follicle stimulating hormone (follitropin alfa) during assisted reproduction technology (ART) procedures. An analysis of 1378 patients. Curr Med Res Opin 2006, 22:907-918.

15. Olivennes F, Howles CM, Borini A, Germond M, Trew G, Wikland M, ZegersHochschild F, Saunders H, Alam V: Individualizing FSH dose for assisted reproduction using a novel algorithm: the CONSORT study. Reprod Biomed Online 2009, 18:195-204

16. De Placido G, Mollo A, Alviggi C, Strina I, Varricchio MT, Ranieri A, Colacurci N, Tolino A, Wilding M: Rescue of IVF cycles by HMG in pituitary down-regulated normogonadotrophic young women characterized by a poor initial response to recombinant FSH. Hum Reprod 2001, 16:1875-1879.

17. De Placido G, Alviggi C, Mollo A, Strina I, Ranieri A, Alviggi E, Wilding M, Varricchio MT, Borrelli AL, Conforti S: Effects of recombinant LH (rLH) supplementation during controlled ovarian hyperstimulation $(\mathrm{COH})$ in normogonadotrophic women with an initial inadequate response to recombinant FSH ( $\mathrm{rFSH}$ ) after pituitary downregulation. Clin Endocrinol (Oxf) 2004, 60:637-643.

18. De Placido G, Clarizia R, Alviggi C: Lutropin alfa: a viewpoint by Giuseppe De Placido, Roberto Clarizia and Carlo Alviggi. Drugs 2008, 68:1541-1542.

19. Ferraretti AP, Gianaroli L, Magli MC, D'angelo A, Farfalli V, Montanaro N: Exogenous luteinizing hormone in controlled ovarian hyperstimulation for assisted reproduction techniques. Fertil Steril 2004, 82:1521-1526.

20. Liao WX, Goh HH, Roy AC: Functional characterization of a natural variant of luteinizing hormone. Hum Genet 2002, 111:219-224

21. Huhtaniemi I, Pettersson K: Mutations and polymorphisms in the gonadotrophin genes; clinical relevance. Clin Endocrinol (Oxf) 1998, 48:675-682.

22. Jiang M, Pakarinen $P$, Zhang FP, El-Hefnawy $T$, Koskimies $P$, Pettersson $K$, Huhtaniemi I: A common polymorphic allele of the human luteinizing 
hormone beta-subunit gene: additional mutations and differential function of the promoter sequence. Hum Mol Genet 1999, 8:2037-2046.

23. Nilsson CH, Kaleva M, Virtanen $H$, Haavisto AM, Pettersson $\mathrm{K}$, Huhtaniemi IT: Disparate response of wild-type and variant forms of LH to GnRH stimulation in individuals heterozygous for the LHbeta variant allele. Hum Reprod 2001, 16:230-235.

24. Alviggi C, Clarizia R, Pettersen K, Mollo A, Humaidan P, Strina I, Coppola M Ranieri A, D'Uva M, De Placido G: Suboptimal response to GnRHa long protocol is associated with a common LH polymorphism. Reprod Biomed Online 2009, 18:9-14

25. Gromoll J, Lahrmann L, Godmann M, Muller T, Michel C, Stamm S, Simoni M: Genomic checkpoints for exon 10 usage in the luteinizing hormone receptor type 1 and type 2. Mol Endocrinol 2007, 21:1984-1996.

26. Nordhoff V, Gromoll J, Simoni M: Constitutively active mutations of G protein-coupled receptors: the case of the human luteinizing hormone and follicle-stimulating hormone receptors. Arch Med Res 1999, 30:501-509.

27. Akerman FM, Lei Z, Rao CV, Nakajima ST: A case of spontaneous ovarian hyperstimulation syndrome with a potential mutation in the hCG/LH receptor gene. Fertil Steril 2000, 74:403-404

28. Gromoll J, Simoni M: Genetic complexity of FSH receptor function. Trends Endocrinol Metab 2005, 16:368-373.

29. Greb RR, Grieshaber K, Gromoll J, Sonntag B, Nieschlag E, Kiesel L, Simoni $\mathrm{M}$ : A common single nucleotide polymorphism in exon 10 of the human follicle stimulating hormone receptor is a major determinant of length and hormonal dynamics of the menstrual cycle. J Clin Endocrinol Metab 2005, 90:4866-4872

30. Falconer H, Andersson E, Aanesen A, Fried G: Follicle-stimulating hormone receptor polymorphisms in a population of infertile women. Acta Obstet Gynecol Scand 2005, 84:806-811.

31. Behre HM, Greb RR, Mempel A, Sonntag B, Kiesel L, Kaltwasser P, Seliger E, Ropke F, Gromoll J, Nieschlag E, Simoni M: Significance of a common single nucleotide polymorphism in exon 10 of the follicle-stimulating hormone (FSH) receptor gene for the ovarian response to FSH: a pharmacogenetic approach to controlled ovarian hyperstimulation. Pharmacogenet Genomics 2005, 15:451-456.

32. Gerasimova T, Thanasoula MN, Zattas D, Seli E, Sakkas D, Lalioti MD: Identification and in vitro characterization of follicle stimulating hormone (FSH) receptor variants associated with abnormal ovarian response to FSH. J Clin Endocrinol Metab 2010, 95:529-536.

33. Manna PR, Joshi L, Reinhold VN, Aubert ML, Suganuma N, Pettersson K, Huhtaniemi IT: Synthesis, purification and structural and functional characterization of recombinant form of a common genetic variant of human luteinizing hormone. Hum Mol Genet 2002, 11:301-315.

34. Nilsson C, Pettersson K, Millar RP, Coerver KA, Matzuk MM, Huhtaniemi IT: Worldwide frequency of a common genetic variant of luteinizing hormone: an international collaborative research. International Collaborative Research Group. Fertil Steril 1997, 67:998-1004.

35. Alviggi C, Clarizia R, Pettersson K, Mollo A, Strina I, De Biasio G, De Placido G, Humaidan P: A single point mutation in the LH beta subunit is associated with higher exogenous FSH consumption during ovarian stimulation. Human Reprod 2009, 24(Suppl 1):i31, abstract O-077.

36. Lalioti MD: Impact of follicle stimulating hormone receptor variants in fertility. Curr Opin Obstet Gynecol 2011, 23:158-167.

37. Simoni M, Gromoll J, Höppner W, Kamischke A, Krafft T, Stähle D, Nieschlag E: Mutational analysis of the follicle-stimulating hormone receptor in normal and infertile men: identification and characterization of two discrete FSH receptor isoforms. J Clin Endocrinol Metab 1999, 84:751-755.

38. Perez Mayorga M, Gromoll J, Behre HM, Gassner C, Nieschlag E, Simoni M: Ovarian response to follicle-stimulating hormone (FSH) stimulation depends on the FSH receptor genotype. J Clin Endocrinol Metab 2000, 85:3365-3369.

39. Gu BH, Park JM, Baek KH: Genetic variations of follicle stimulating hormone receptor are associated with polycystic ovary syndrome. Int $J$ Mol Med 2010, 26:107-112.

40. Valkenburg O, Uitterlinden AG, Piersma D, Hofman A, Themmen AP, de Jong FH, Fauser BC, Laven JS: Genetic polymorphisms of GnRH and gonadotrophic hormone receptors affect the phenotype of polycystic ovary syndrome. Hum Reprod 2009, 24:2014-2022.
41. Overbeek A, Kuijper EA, Hendriks ML, Blankenstein MA, Ketel IJ, Twisk JW, Hompes PG, Homburg R, Lambalk CB: Clomiphene citrate resistance in relation to follicle-stimulating hormone receptor Ser680Serpolymorphism in polycystic ovary syndrome. Hum Reprod 2009, 24:2007-2013.

42. Mohiyiddeen L, Nardo LG: Single-nucleotide polymorphisms in the FSH receptor gene and ovarian performance: future role in IVF. Hum Fertil (Camb) 2010, 13:72-78.

43. Jun JK, Yoon JS, Ku SY, Choi YM, Hwang KR, Park SY, Lee GH, Lee WD, Kim SH, Kim JG, Moon SY: Follicle-stimulating hormone receptor gene polymorphism and ovarian responses to controlled ovarian hyperstimulation for IVF-ET. J Hum Genet 2006, 51:665-670.

44. Klinkert ER, te Velde ER, Weima S, van Zandvoort PM, Hanssen RG, Nilsson PR, de Jong FH, Looman CW, Broekmans FJ: FSH receptor genotype is associated with pregnancy but not with ovarian response in IVF. Reprod Biomed Online 2006, 13:687-695.

45. Detti L, Williams DB, Robins JC, Maxwell RA, Thomas MA: A comparison of three downregulation approaches for poor responders undergoing in vitro fertilization. Fertil Steril 2005, 84:1401-1405.

46. Loutradis D, Vomvolaki E, Drakakis P: Poor responder protocols for in-vitro fertilization: options and results. Curr Opin Obstet Gynecol 2008, 20:374-378.

doi:10.1186/1477-7827-10-9

Cite this article as: Alviggi et al:: Hormonal, functional and genetic biomarkers in controlled ovarian stimulation: tools for matching patients and protocols. Reproductive Biology and Endocrinology 2012 10:9.

\section{Submit your next manuscript to BioMed Central and take full advantage of:}

- Convenient online submission

- Thorough peer review

- No space constraints or color figure charges

- Immediate publication on acceptance

- Inclusion in PubMed, CAS, Scopus and Google Scholar

- Research which is freely available for redistribution

Submit your manuscript at www.biomedcentral.com/submit
Ciomed Central 